\title{
Arginase inhibition restores NOS coupling and reverses endothelial dysfunction and vascular stiffness in old rats
}

\author{
Jae Hyung Kim, ${ }^{1}$ Lukasz J. Bugaj, ${ }^{2}$ Young Jun Oh, ${ }^{1,6}$ Trinity J. Bivalacqua, ${ }^{3}$ Sungwoo Ryoo, ${ }^{7}$ \\ Kevin G. Soucy, ${ }^{2}$ Lakshmi Santhanam, ${ }^{1}$ Alanah Webb, ${ }^{2}$ Andre Camara, ${ }^{1}$ Gautam Sikka, ${ }^{1}$ Daniel Nyhan, ${ }^{1}$ \\ Artin A. Shoukas, ${ }^{2}$ Monica Ilies, ${ }^{4}$ David W. Christianson, ${ }^{4}$ Hunter C. Champion, ${ }^{5}$ and Dan E. Berkowitz ${ }^{1,2}$ \\ Departments of ${ }^{1}$ Anesthesiology and Critical Care Medicine, ${ }^{2}$ Biomedical Engineering, ${ }^{3}$ Urology, Johns Hopkins Medical \\ Institutions, Baltimore, Maryland; ${ }^{4}$ Department of Chemistry, University of Pennsylvania, Philadelphia, Pennsylvania; \\ ${ }^{5}$ Department of Medicine, University of Pittsburgh School of Medicine, Pittsburgh, Pennsylvania; ${ }^{6}$ Department \\ of Anesthesiology and Pain Medicine, Yonsei University, Seoul, Korea; and ${ }^{7}$ Biology Program, Division of Life Sciences, \\ Kangwon National University, Chuncheon, Korea
}

Submitted 17 October 2008; accepted in final form 28 July 2009

Kim JH, Bugaj LJ, Oh YJ, Bivalacqua TJ, Ryoo S, Soucy KG, Santhanam L, Webb A, Camara A, Sikka G, Nyhan D, Shoukas AA, Ilies M, Christianson DW, Champion HC, Berkowitz DE. Arginase inhibition restores NOS coupling and reverses endothelial dysfunction and vascular stiffness in old rats. J Appl Physiol 107: 1249-1257, 2009. First published August 6, 2009; doi:10.1152/japplphysiol.91393.2008.-There is increasing evidence that upregulation of arginase contributes to impaired endothelial function in aging. In this study, we demonstrate that arginase upregulation leads to endothelial nitric oxide synthase (eNOS) uncoupling and that in vivo chronic inhibition of arginase restores nitroso-redox balance, improves endothelial function, and increases vascular compliance in old rats. Arginase activity in old rats was significantly increased compared with that shown in young rats. Old rats had significantly lower nitric oxide (NO) and higher superoxide $\left(\mathrm{O}_{2}^{-}\right)$production than young. Acute inhibition of both NOS, with $N^{\mathrm{G}}$-nitro-L-arginine methyl ester, and arginase, with $2(S)$-amino6-boronohexanoic acid $(\mathrm{ABH})$, significantly reduced $\mathrm{O}_{2}^{-}$production in old rats but not in young. In addition, the ratio of eNOS dimer to monomer in old rats was significantly decreased compared with that shown in young rats. These results suggest that eNOS was uncoupled in old rats. Although the expression of arginase 1 and eNOS was similar in young and old rats, inducible NOS (iNOS) was significantly upregulated. Furthermore, $S$-nitrosylation of arginase 1 was significantly elevated in old rats. These findings support our previously published finding that iNOS nitrosylates and activates arginase 1 (Santhanam et al., Circ Res 101: 692-702, 2007). Chronic arginase inhibition in old rats preserved eNOS dimer-to-monomer ratio and significantly reduced $\mathrm{O}_{2}^{-}$production and enhanced endothelial-dependent vasorelaxation to $\mathrm{ACh}$. In addition, $\mathrm{ABH}$ significantly reduced vascular stiffness in old rats. These data indicate that iNOS-dependent $S$-nitrosylation of arginase 1 and the increase in arginase activity lead to eNOS uncoupling, contributing to the nitroso-redox imbalance, endothelial dysfunction, and vascular stiffness observed in vascular aging. We suggest that arginase is a viable target for therapy in age-dependent vascular stiffness.

aging; nitric oxide; $S$-nitrosylation; NOS uncoupling

VASCULAR STIFFNESS (33) and decreased nitric oxide (NO) bioavailability $(3,19)$ are hallmarks of the aging cardiovascular system. Reactive oxygen species (ROS) production is also enhanced in aged blood vessels (12, 23). Superoxide $\left(\mathrm{O}_{2}^{-}\right)$is a free radical that rapidly scavenges $\mathrm{NO}$, thereby

Address for reprint requests and other correspondence: D. E. Berkowitz, Anesthesiology, Tower 711, Johns Hopkins Hospital, 600 N. Wolfe St., Baltimore, MD 21287 (e-mail: dberkow1@jhmi.edu). decreasing $\mathrm{NO}$ bioavailability. $\mathrm{NO}$ and $\mathrm{O}_{2}^{-}$may react to produce peroxynitrite $\left(\mathrm{ONOO}^{-}\right)$, a highly damaging ROS molecule. Thus simultaneous generation of $\mathrm{NO}$ and $\mathrm{O}_{2}^{-}$can raise $\mathrm{ONOO}^{-}$to levels potentially detrimental to vascular cell function and viability (22). This nitroso-redox imbalance contributes to aging-related endothelial dysfunction and vascular stiffness (6).

Under normal physiological conditions, nitric oxide synthase (NOS) produces the potent vasodilator NO by catalyzing L-arginine to L-citrulline. This normal function of endothelial NOS (eNOS, NOS3) requires dimerization of the enzyme, the substrate L-arginine, and the essential cofactor $(6 R)-5,6,7,8$ tetrahydro-L-biopterin (BH4) (24). However, the enzyme arginase uses L-arginine as a substrate (4) and reciprocally regulates NOS by substrate depletion $(6,15,55)$. There is increasing evidence that upregulation of arginase functionally inhibits NOS activity and contributes to the pathophysiology of agerelated vascular dysfunction $(6,45,55)$. Furthermore, pharmacological inhibition and antisense knockdown of arginase 1 (Arg1) restore endothelial NO production and endothelial function ex vivo (55). Interestingly, Arg1 appears to be regulated by inducible NOS (iNOS). We have previously demonstrated that iNOS-derived NO nitrosylates arginase at cysteine 303, subsequently activating arginase (most likely by stabilizing the trimeric form of the enzyme). This selective inhibition of iNOS diminished arginase activity and significantly improved vascular function in aged vessels. Furthermore, this iNOS-dependent activation of arginase was specific to the vascular endothelium (45). Consequently, elevated iNOS expression in aging is likely to precede amplified arginase activity.

Given the role of arginase in reciprocally regulating eNOS activity and its contribution to endothelial dysfunction, in this study, we tested the hypothesis that arginase upregulation in old rats leads to eNOS uncoupling. Furthermore, we determined whether in vivo chronic inhibition of arginase restores nitroso-redox balance, endothelial function, and vascular stiffness in old rats to that of the young phenotype.

\section{MATERIALS AND METHODS}

Animals. Twenty-eight old ( $22-24 \mathrm{mo})$ and twenty-eight young (3 mo) male Fischer 344 rats were purchased from the National Institute on Aging and used in the study. The Fischer 344 strain has been widely used in aging studies and has been shown by Miller et al. (35) to have a progressive rather than an abrupt development of age-related pathophysiology, both in differential gene expression and 
in structural alterations (35). All of the surgical procedures and experimental protocols were approved by the Institutional Animal Care and Use Committee and are fully accredited by the American Association for Accreditation in Laboratory Animal Care. The retention and use of the animals are in compliance with federal, state, and local laws and regulations and in accordance with the National Research Council Guide.

Chronic arginase inhibition. Rats were equally divided into four groups: 14 young control (YC), 14 young treated with arginase inhibitor (YABH), 14 old control (OC), and 14 old treated with arginase inhibitor $(\mathrm{OABH})$. Treatment groups were given water with 2(S)-amino-6-boronohexanoicacid $(\mathrm{ABH} ; 20 \mathrm{mg} / \mathrm{l})(5,21)$ for 25 days. Each rat consumed $\sim 400 \mu \mathrm{g}$ of $\mathrm{ABH}$ daily. Control groups were given normal tap water. There was no obvious difference in the consumption of water between the treatment and control groups. $\mathrm{ABH}$ $\left[K_{\mathrm{d}}=5 \mathrm{nM}\right.$ against human Arg1 (21)] was synthesized by our previously reported method (5), which we further optimized to facilitate the scale-up of inhibitor synthesis: the use of an alternative hydroboration reagent (pinacolborane in the presence of Wilkinson's catalyst) increased the overall yield of the synthesis more than 10-fold over our best previous overall yield of $4.7 \%$ (57).

Preparation of aorta and carotid artery. Heparin was administered to the rats $1 \mathrm{~h}$ before death. The animals were euthanized, and the thoracic aorta, from distal aortic arch to the diaphragmatic level, was dissected and immersed in Krebs solution containing (in mmol) 118 $\mathrm{NaCl}, 4.7 \mathrm{KCl}, 1.2 \mathrm{KH}_{2} \mathrm{PO}_{4}, 2.5 \mathrm{CaCl}_{2}, 1.2 \mathrm{MgSO}_{4}, 25 \mathrm{NaHCO}_{3}$, and 11.1 glucose. Both carotid arteries were dissected and immersed in HEPES buffer (in mmol: $136 \mathrm{NaCl}, 5.9 \mathrm{KCl}, 1.2 \mathrm{MgCl}_{2}, 11.6 \mathrm{HEPES}$, 11.5 dextrose, $1.66 \mathrm{CaCl}_{2}$, adjusted to $\mathrm{pH} 7.4$ with $\mathrm{NaOH}$ before $\mathrm{CaCl}_{2}$ addition). The vessels were carefully cleaned of connective tissue and cut into 5-mm rings. Aortic rings were prepared for use in isometric tension ring experiments and $\mathrm{O}_{2}^{-}$production rate. Extra aorta tissue was immediately frozen in liquid nitrogen and stored at $-80^{\circ} \mathrm{C}$ until assayed biochemically for arginase activity and Western blot analysis. Carotid artery rings were used for measurement of basal $\mathrm{NO}$ and $\mathrm{O}_{2}^{-}$production rate.

Arginase activity assay. Arginase activity was measured by determining levels of urea production as previously described (55). Briefly, rat aortic sections were sonicated for $10 \mathrm{~min}$ in lysis buffer $(50 \mathrm{mmol}$ Tris $\cdot \mathrm{HCl}, \mathrm{pH} 7.5,0.1$ mmol EDTA, $0.1 \%$ Triton $\mathrm{X}-100$, and protease inhibitor) and centrifuged for $30 \mathrm{~min}$ at $14,000 \mathrm{~g}$ at $4^{\circ} \mathrm{C}$. Supernatant $(50 \mu \mathrm{l})$ was then added to $75 \mu \mathrm{l}$ of Tris $\cdot \mathrm{HCl}(50 \mathrm{mmol}, \mathrm{pH} 7.5)$ containing $10 \mathrm{mmol} \mathrm{MnCl}_{2}$, and the mixture was activated by heating for $10 \mathrm{~min}$ at $55-60^{\circ} \mathrm{C}$. The mixture was incubated with L-arginine $(50 \mu \mathrm{l}, 0.5 \mathrm{M}, \mathrm{pH} 9.7)$ at $37^{\circ} \mathrm{C}$ for $1 \mathrm{~h}$, and the reaction was stopped by adding $400 \mu \mathrm{l}$ of an acid solution $\left(\mathrm{H}_{2} \mathrm{SO}_{4}-\mathrm{H}_{3} \mathrm{PO}_{4}-\mathrm{H}_{2} \mathrm{O}=1: 3: 7\right)$. For colorimetric determination of urea, $\alpha$-isonitrosopropiophenone (25 $\mu 1,9 \%$ in ethanol) was added, and the mixture was heated at $100^{\circ} \mathrm{C}$ for $45 \mathrm{~min}$. After the sample was placed in the dark for $10 \mathrm{~min}$ at room temperature, the urea concentration was determined spectrophotometrically by measuring absorbance at $550 \mathrm{~nm}$.

$N O$ and ROS production in isolated rat carotid artery and aorta. The rate of basal $\mathrm{NO}$ and $\mathrm{O}_{2}^{-}$production was fluorescently measured ex vivo in the following manner. Isolated vascular rings were cut and pinned flat, endothelium facing up, in 35-mm culture dishes (Corning) with a Silastic base (Sylgard 184, Dow Corning, Midland, MI). NO production was assayed in the carotid artery using the NO-sensitive fluorescent dye DAF FM-DA (Molecular Probes, Eugene, OR). $\mathrm{O}_{2}^{-}$ production was measured in the carotid artery or aorta using $\mathrm{O}_{2}^{-}$sensitive dihydroethidium bromide (DHE) (Molecular Probes). Vessels were incubated for $5 \mathrm{~min}$ at $37^{\circ} \mathrm{C}$ in $2 \mathrm{ml}$ of HEPES buffer containing the appropriate dye $(5 \mu \mathrm{mol} / \mathrm{l}$ DAF-DM DA or $5 \mu \mathrm{mol} / 1$ DHE). After incubation, the buffer was replaced, and the dish was placed in a DH-40i heating chamber (Warner Instruments, Hamden, CT) maintained at $37^{\circ} \mathrm{C}$. Time-lapse fluorescence was measured using an epifluorescence microscope (Nikon Eclipse 80i, Tokyo, Japan), with images recorded every $30 \mathrm{~s}$ using NIS Elements software
(Nikon). Rate of DAF and DHE fluorescence were measured from the endothelium over $10 \mathrm{~min}$. We also measured the rate of $\mathrm{NO}$ and $\mathrm{O}_{2}^{-}$production in response to $N^{\mathrm{G}}$-nitro-L-arginine methyl ester (L-NAME; $100 \mu \mathrm{mol} / \mathrm{l}$ ) (Sigma-Aldrich, Buchs, Switzerland). By plotting the fluorescence over time, the slope of the line of best fit represents the rate of $\mathrm{NO}$ or $\mathrm{O}_{2}^{-}$production. The raw fluorescence counts and slopes were normalized by initial fluorescence counts [in arbitrary units $(\mathrm{au})$ ].

Western blot analysis. Aortas from YC, YABH, OC, and $\mathrm{OABH}$ animals were homogenized and centrifuged for $30 \mathrm{~min}$ at 14,000 $\mathrm{g}$ at $4^{\circ} \mathrm{C}$. The protein amount of the supernatant was analyzed by the Bradford method. Protein $(100 \mu \mathrm{g})$ from the aorta homogenate was separated and transferred. The blots were incubated with their respective polyclonal anti-iNOS (BD Bioscience, San Jose, CA), anti-actin (BD Bioscience), anti-eNOS (BD Bioscience), anti-Arg1 (Santa Cruz Biotechnology, Santa Cruz, CA), or anti-glyceraldehyde-3-phosphate dehydrogenase (GAPDH) (Novus Biologicals, Littleton, CO) antibodies, followed by a horseradish peroxidase-conjugated secondary antibody. Signals were detected using chemiluminescence. To quantify the resultant blots, individual band intensities were measured (arbitrary units) and the iNOS-to-actin, eNOS-to-GAPDH, and Arg1-toGAPDH ratios were calculated per sample using ImageJ software (National Institutes of Health). The ratios were normalized to the mean $\mathrm{YC}$ ratio.

Selective fluorescent labeling of S-nitrosothiols assay. Aortas from rats treated with $\mathrm{ABH}$ and untreated controls were homogenized. $S$-nitrosylation of Arg1 (SNO-Arg1) was determined using the selective fluorescent labeling of $S$-nitrosothiols assay (44). In brief, $100 \mu \mathrm{g}$ of proteins were blocked using $50 \mathrm{mM}$ methylmethane thiosulfonate and recovered by cold acetone precipitation. Protein samples $(15 \mu \mathrm{g})$ were reduced with $2 \mathrm{mM}$ ascorbate and labeled with Cy5 (GE Healthcare, Piscataway, NJ). Aliquots of these samples (15 $\mu \mathrm{g})$, not reduced, were labeled with $\mathrm{Cy} 3$ (GE Healthcare) to determine nonspecific labeling. Unreacted Cy dyes were removed using buffer exchange columns, mixed, and Arg1 immunoprecipitated. Proteins were eluted and resolved by SDS-PAGE. Gel was scanned using a Typhoon scanner (GE Healthcare) and poststained with silver, as previously described (44). Data for YC animals for SNO-Arg1 were arbitrary set at $100 \%$.

Determination of eNOS dimerization. The ratio of eNOS dimer to eNOS monomer was determined in young, old, and $\mathrm{OABH}$ rats. Dimers and monomers of eNOS were separated using low-temperature SDS-PAGE under reducing or nonreducing conditions, as previously described (50).

In vitro vascular reactivity in rat aorta. Aortic rings, prepared as described above, were suspended from strain gauges for isometric tension recording in organ chambers filled with $25 \mathrm{ml}$ Krebs-Ringer bicarbonate solution $\left(95 \% \quad \mathrm{O}_{2}-5 \% \quad \mathrm{CO}_{2}, \mathrm{pH}\right.$ 7.4). Protocols were performed on rings beginning at their optimum resting tone, previously determined to be $3 \mathrm{~g}$ for rat aorta. This resting tone was reached by stretching rings in 500-mg increments separated by 10 -min intervals. Data were collected using a MacLab system and analyzed using Dose Response Software (AD Instruments, Colorado Springs, CO). Vessel rings were preconstricted with phenylephrine (PE; $1 \mu \mathrm{mol} / \mathrm{l}$ ) (Sigma, St. Louis, MO), and their vasorelaxant dose responses to ACh ( $1 \mathrm{nmol} / \mathrm{l}$ to $10 \mu \mathrm{mol} / \mathrm{l}$ ) (Sigma) were recorded. After washout and return to resting tension, vessels were again preconstricted with $\mathrm{PE}$, and their response to an NO donor, sodium nitroprusside (SNP) (Sigma), was determined ( $1 \mathrm{nmol} / \mathrm{l}$ to $10 \mu \mathrm{mol} / \mathrm{l})$.

Pulse wave velocity. In vivo vascular stiffness was determined before and after treatment by measuring pulse wave velocity (PWV) using an ECG-triggered 10-MHz Doppler probe (Indus Instruments, Houston, TX) at thoracic and abdominal aorta locations. The animals were anesthetized during the measurements with $\sim 1-1.5 \%$ isoflurane. Animals were positioned supine with limbs taped to electrocardiogram electrodes incorporated into a temperature-controlled printed circuit board (THM100, Indus Instruments). Rectal temperature was 


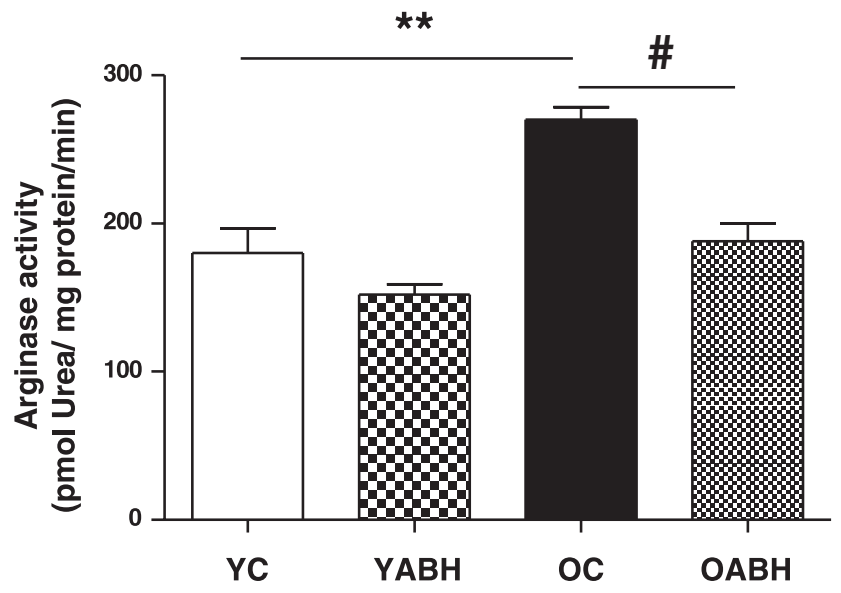

Fig. 1. Arginase activity was significantly increased in old rats (YC vs. OC, $n=4, * * P<0.01)$. Chronic treatment with $2(S)$-amino-6-boronohexanoic acid $(\mathrm{ABH})$ inhibited arginase in old rats $(\mathrm{OC}$ vs. $\mathrm{OABH}, n=4, \# P<0.01)$. $\mathrm{YC}$, young control rats; $\mathrm{YABH}$, young rats treated with $\mathrm{ABH}$; OC, old control rats; $\mathrm{OABH}$, old rats treated with $\mathrm{ABH}$.

monitored with a probe (Physitemp, Clifton, NJ) and maintained at $37^{\circ} \mathrm{C}$ throughout the procedure. Both thoracic and abdominal aortic flows were acquired at a depth of $\sim 2-4$ and $\sim 5-6 \mathrm{~mm}$, respectively, with a 2-mm-diameter, 10-MHz Doppler probe (Indus Instruments). These sites of measurement were marked, and the separation distance between them was measured. PWV (in $\mathrm{m} / \mathrm{s}$ ) was calculated as quotient of separation distance and time difference between pulse arrivals, as measured from the ECG R-peaks. Data analyses of Doppler and ECG signals were performed off-line using DSPW software from Indus Instruments.

Statistical analysis. Data are presented as means \pm SE of $n$ independent experiments performed from different donors. All data were analyzed off-line with PRISM data analysis software (GraphPad 4, GraphPad Software, La Jolla, CA). A value of $P>0.05$ was considered statistically significant. Arginase activity, fluorescence, Western blot, and PWV data were analyzed with 1-way ANOVA, Wilcoxon, and Mann-Whitney tests, as appropriate. Vascular response data were analyzed using two-way ANOVA with Bonferroni correction for multiple comparisons.

\section{RESULTS}

Arginase activity in aorta. We first measured arginase activity in YC, YABH, OC, and OABH groups (Fig. 1). There was a significant increase in arginase activity in $\mathrm{OC}$ compared with YC aorta (YC vs. OC: $180 \pm 16.5$ vs. $270 \pm 8.5$ pmol urea $\cdot \mathrm{mg}$ protein $\left.{ }^{-1} \cdot \min ^{-1} ; n=4, P<0.01\right)$. These results are consistent with previous findings $(6,55)$ and validate the hypothesis that arginase activity is increased in old rat vessels. Chronic treatment of old rats with $\mathrm{ABH}$ significantly decreased arginase activity compared to that shown in OC rats (OC vs. OABH: $270 \pm 8.5$ vs. $188 \pm 12.0$ pmol urea $\cdot \mathrm{mg}$ protein $\left.^{-1} \cdot \min ^{-1} ; n=4, P<0.01\right)$.

Chronic inhibition of arginase restores $N O$ production in carotid artery. Using a DAF-FM DA bioassay, we measured basal $\mathrm{NO}$ production in $\mathrm{YC}$ and $\mathrm{OC}$ carotid arteries. OC vessels exhibited a significant decrease in $\mathrm{NO}$ production compared with that shown in YC (YC vs. OC: $2.2 \pm 0.3$ vs. $0.5 \pm 0.2 \mathrm{au} ; n=6, P<0.01$ ) (Fig. $2 A$ ). Chronic inhibition of arginase in old rats significantly increased endothelial NO production (OC vs. OABH: $0.5 \pm 0.2$ vs. $1.9 \pm 0.1$ au; $n=6$, $P<0.05$ ) (Fig. 2A), suggesting that the aging-induced endothelial NO production decrease is arginase dependent. Subsequent inhibition of eNOS with L-NAME (100 $\mu \mathrm{mol} / \mathrm{l})$ significantly reduced $\mathrm{NO}$ production in $\mathrm{YC}, \mathrm{YABH}$, and $\mathrm{OABH}$ animals $(P<0.05$ in $\mathrm{YC}, P<0.01$ in $\mathrm{YABH}, P<0.01$ in $\mathrm{OABH} ; n=6$ ). OC aortas followed this trend, although the decrease was not significant (Fig. 2C).

Acute inhibition of arginase decreases ROS production in isolated aorta. To determine whether arginase activity contributes to eNOS uncoupling, we measured $\mathrm{O}_{2}^{-}$production rate using DHE fluorescence in old and young rat aortas incubated in $\mathrm{ABH}(10 \mu \mathrm{mol} / \mathrm{l})$, L-NAME $(100 \mu \mathrm{mol} / \mathrm{l})$, or with no treatment (Fig. 3). OC vessels $(n=7)$ exhibited a significantly higher rate of DHE fluorescence than that shown in YC $(n=$ 6) vessels (OC vs. YC: $4.7 \pm 0.6$ vs. $2.4 \pm 0.6$ au; $P<0.05$ ). Acute inhibition of arginase significantly attenuated age-induced ROS production in $\mathrm{OC}$ [without $\mathrm{ABH}$ vs. with $\mathrm{ABH}$ : $4.7 \pm 0.6(n=7)$ vs. $1.7 \pm 0.6(n=4)$ au; $P<0.05]$, as did
A

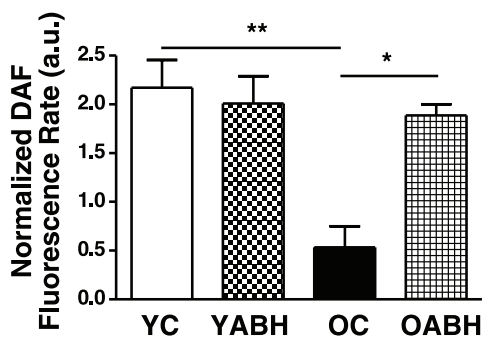

B

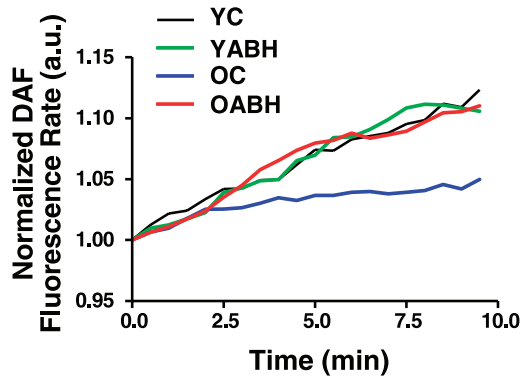

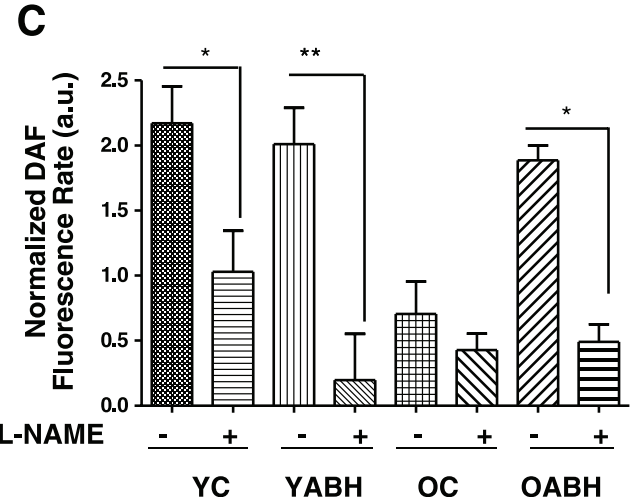

Fig. 2. Chronic in vivo arginase inhibition increases nitric oxide $(\mathrm{NO})$ production. NO production was measured in $\mathrm{YC}, \mathrm{OC}, \mathrm{YABH}$, and $\mathrm{OABH}$ carotid arteries using a DAF-FM DA bioassay. The raw fluorescence counts and slope were normalized to initial fluorescence counts (in arbitrary units, au). A: OC vessels exhibited significantly decreased NO production compared with that shown in YC rats (YC vs. OC: $2.2 \pm 0.3$ vs. $0.5 \pm 0.2$ au; $n=6, * * P<0.01$ ). Chronic arginase inhibition restores NO signaling in old rat carotid artery (OC vs. OABH: $0.5 \pm 0.2$ vs. $1.9 \pm 0.1$ au; $n=6$, * $P<0.05$ ). $B$ : representative traces of DAF fluorescence from YC, YABH, OC, and OABH. OC vessels exhibit a significant decrease in NO production. $C$ : acute treatment of carotid arteries with the nitric oxide synthase (NOS) inhibitor $N^{\mathrm{G}}$-nitro-L-arginine methyl ester (L-NAME; $100 \mu \mathrm{mol} / \mathrm{l}$ ) leads to significant reduction in NO production in YC, YABH, and $\mathrm{OABH}$ samples $\left(* P<0.05\right.$ in $\mathrm{YC},{ }^{* *} P<0.01$ in $\mathrm{YABH}, * P<0.05$ in $\mathrm{OABH}$ ), but the change was not significant in $\mathrm{OC}$. 


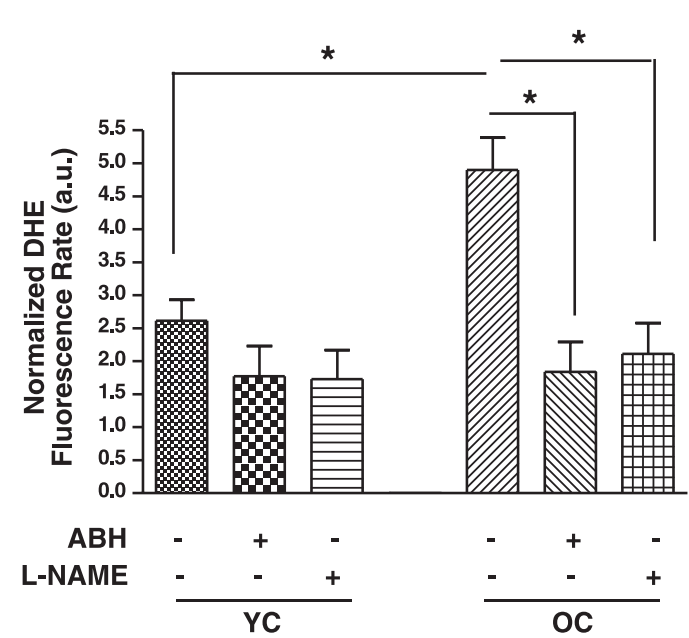

Fig. 3. Acute arginase inhibition in old rats restores endothelial NOS (eNOS) coupling. Reactive oxygen species (ROS) production was measured in young and old rat aortas using the $\mathrm{O}_{2}^{-}$-specific fluorescent dye dihydroethidium bromide (DHE). The raw fluorescence slopes were normalized by initial fluorescence counts (in au). OC vessels exhibited a significant increase in ROS production compared with that shown in YC rats [OC vs. YC: $4.7 \pm 0.6(n=$ 7) vs. $2.4 \pm 0.6(n=6)$ au; $* P<0.05]$. Arginase inhibition significantly attenuated age-associated ROS production [OC without $\mathrm{ABH}(\mathrm{ABH}-)$ vs. OC with $\mathrm{ABH}(\mathrm{ABH}+): 4.7 \pm 0.6(n=7)$ vs. $1.7 \pm 0.6(n=4)$ au; $* P<0.05]$, as did eNOS inhibition [OC without L-NAME (L-NAME-) vs. OC with L-NAME (L-NAME+): $4.7 \pm 0.6(n=7)$ vs. $1.8 \pm 0.6(n=6)$ au; $* P<0.05]$ These results suggest that eNOS uncoupling and arginase activity are directly linked.

NOS inhibition [without L-NAME vs. with L-NAME: $4.7 \pm 0.6$ $(n=7)$ vs. $1.8 \pm 0.6(n=6)$ au; $P<0.05]$. In YC aortas, $\mathrm{O}_{2}^{-}$ production rates did not vary significantly with either $\mathrm{ABH}$ or L-NAME ( $n=6, P>0.05)$. These results suggest that NOS uncoupling is the source of the endothelial ROS in the aging blood vessels, and arginase may contribute to this age-related dysfunction.

Chronic inhibition of arginase decreases ROS production in carotid artery. We next investigated whether chronic arginase inhibition in old rats decreases $\mathrm{O}_{2}^{-}$production in the carotid artery. In support of our hypothesis, OC rats $(n=7)$ had significantly higher $\mathrm{O}_{2}^{-}$production than $\mathrm{YC}$ rats $(n=6)(\mathrm{OC}$ vs. YC: $1.9 \pm 0.3$ vs. $0.8 \pm 0.2$ au; $P<0.05$ ) (Fig. $4 A$ ). After chronic administration of $\mathrm{ABH}$, ROS production decreased significantly in old vessels [OC vs. OABH: $1.9 \pm 0.3(n=7)$ vs. $0.6 \pm 0.2(n=5)$ au; $P<0.01]$, suggesting that arginase activity is directly involved in age-induced $\mathrm{O}_{2}^{-}$production. $\mathrm{ABH}$ treatment in young rats had no significant effect on the rate of $\mathrm{O}_{2}^{-}$production. [for $\mathrm{YC}$ vs. YABH $(n=5$ or 6$), P>$ 0.05]. Acute treatment of carotid arteries with the NOS inhibitor L-NAME $(100 \mu \mathrm{mol} / \mathrm{l})$ led to significant reduction of ROS production in $\mathrm{OC}(P<0.01 ; n=7)$ but not in $\mathrm{YC}, \mathrm{YABH}$, and OABH samples (Fig. 4C). This suggests that NOS uncoupling is the source of the endothelial ROS in the aging blood vessels.

iNOS mediates nitrosylation and activation of Arg1 in aorta of old rats. We performed Western blot for Arg1, eNOS, and iNOS. The expression of eNOS and Arg1 is constant in YC, $\mathrm{YABH}, \mathrm{OC}$, and $\mathrm{OABH}$ groups (Fig. $5 B$ ). We confirmed our previous finding (45) that iNOS is indeed expressed in the aorta of old but not young rats (YC vs. OC: $1 \pm 0$ vs. $1.93 \pm 0.1$; YC vs. OABH: $1 \pm 0$ vs. $2.92 \pm 0 ; P<0.001, n=4$ ) (Fig. $5 A$ ). We further tested the hypothesis that increased iNOS expression contributes to SNO-Arg1, thereby increasing its activity. SNO-Arg1 is significantly greater in OC (YC vs. OC: $100 \pm 0.6$ vs. $192 \pm 31 ; n=3, P<0.05$ ). Interestingly, despite elevated iNOS abundance in old rats, $\mathrm{ABH}$ treatment in old rats leads to a decrease in SNO-Arg1 (OC vs. OABH: $192 \pm 31$ vs. $84.5 \pm 2.1 ; n=3, P<0.05$ ) (Fig. $5 C$ ).

Chronic arginase inhibition restores eNOS coupling. We further tested the hypothesis that inhibition of arginase would maintain physiological eNOS function in aging rat aorta by measuring eNOS dimer-to-monomer ratio. The ratio of eNOS dimer to monomer in old rats was significantly decreased compared with that shown in young rats (YC vs. OC: $4.3 \pm 1.0$ vs. $0.5 \pm 0.2 ; n=5, P<0.05)$. Inhibition of arginase with $\mathrm{ABH}$ prevented the decrease in eNOS dimer-to-monomer ratio in old rats (OC vs. $\mathrm{OABH}$ : $0.5 \pm 0.2$ vs. $3.3 \pm 1.0 ; n=5$ or $6, P<$ 0.05 ) (Fig. 6), suggesting that inhibition of arginase in old rats restores eNOS coupling by preventing monomerization.

Chronic arginase inhibition restores endothelial function in aged rats. Because upregulated arginase activity increases ROS production and decreases bioavailability of NO, both
A

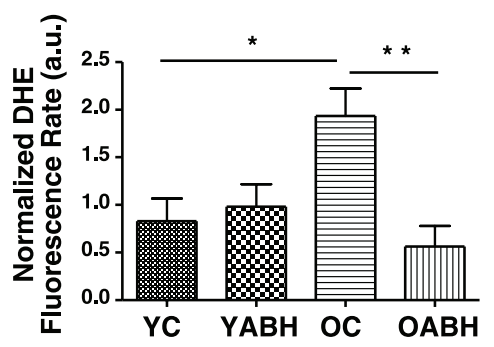

B

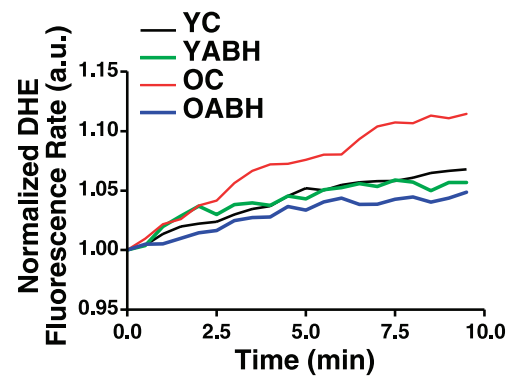

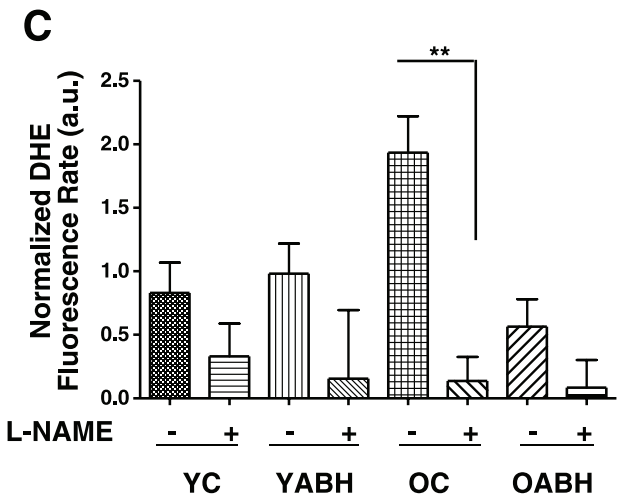

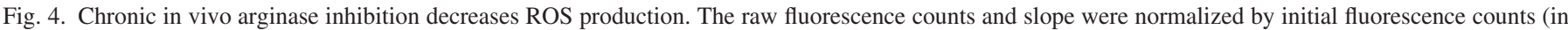

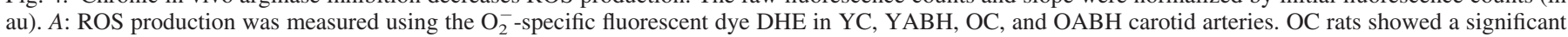

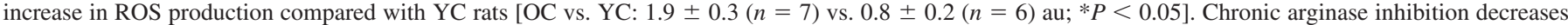

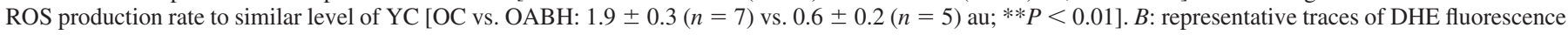

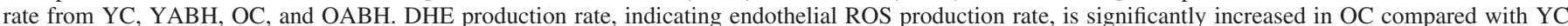

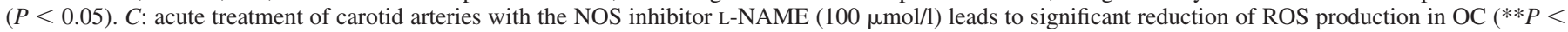
$0.01, n=7$ ) but not significant in $\mathrm{YC}, \mathrm{YABH}$, and $\mathrm{OABH}$. 
A

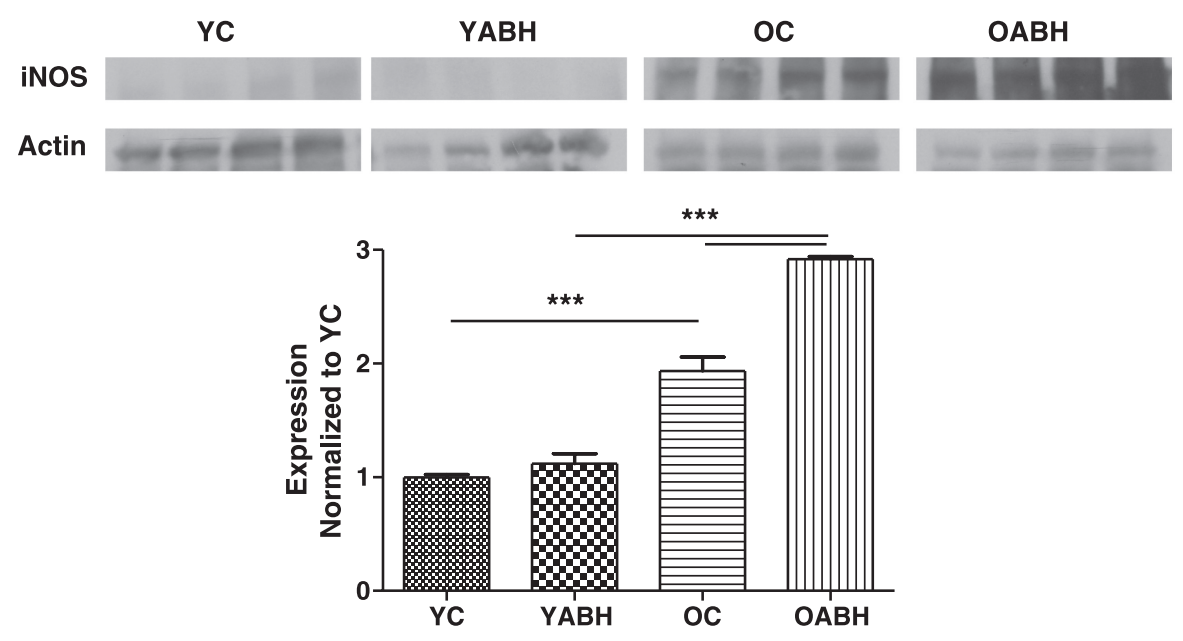

B

C
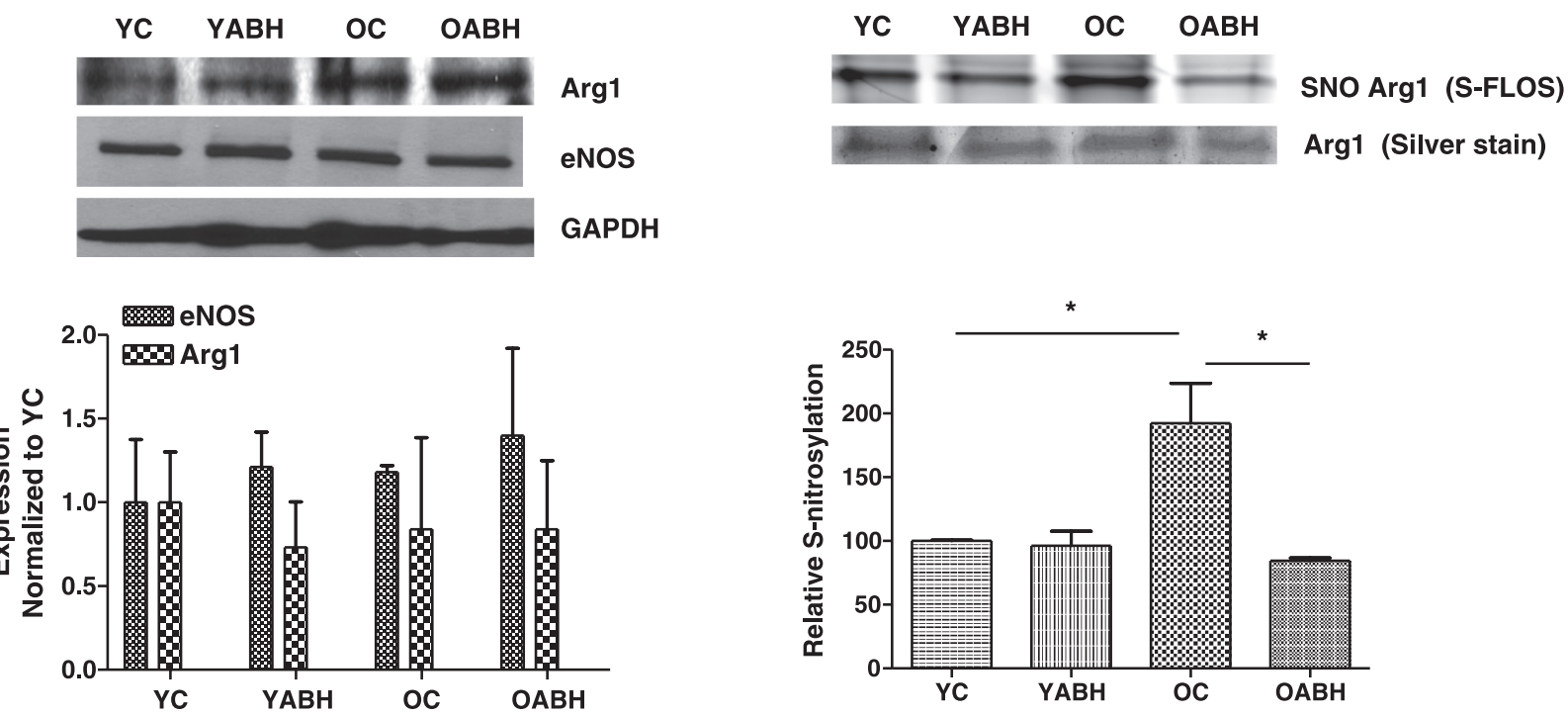

Fig. 5. Inducible NOS (iNOS), eNOS, and arginase 1 (Arg1) expression were determined by Western blotting. A: expression of iNOS in OC and OABH aorta is significantly increased compared with that shown in $\mathrm{YC}$ ( $\mathrm{YC}$ vs. OC and $\mathrm{YC}$ vs. OABH, *** $P<0.001, n=4$ ). $B$ : expression of Arg1 and eNOS are constant in all groups $(P>0.05, n=3)$. Results are representative of 3 independent experiments. $C$ : Cy5 fluorescent signal represents Arg $1 S$-nitrosylation (top), Cy3 represents nonspecific labeling (none detected, data not shown), and silver stain densitometry represents Arg1 amount. Cy5/silver stain densitometry was used to normalize the $S$-nitrosylation value. YC data were arbitrarily set at $100 \%$. Data are representative of 3 independent experiments. $S$-nitrosylation is significantly increased in $\mathrm{OC}\left({ }^{*} P<0.05, n=3\right)$. Chronic in vivo arginase inhibition decreases $S$-nitrosylation $(* P<0.05, n=3)$.

characteristics of endothelial dysfunction in our aging model, we determined whether chronic in vivo inhibition of arginase could attenuate this dysfunction. OC rats exhibited a significantly impaired maximal dilator response $\left(\mathrm{E}_{\max }\right)$ compared with YC rats [OC vs. YC: $\mathrm{E}_{\max }$ of $64.0 \pm 2.6 \%(n=7)$ vs. $\mathrm{E}_{\max }$ of $\left.94.3 \pm 1.8 \%(n=7) ; P<0.01\right]$ (Fig. 7A). Chronic in vivo inhibition of arginase with $\mathrm{ABH}$ in old rats restored endothelial-dependent relaxation compared with that shown in OC animals [OABH vs. OC: $80.3 \pm 2.4 \%(n=7)$ vs. $64.0 \pm$ $2.6 \%(n=7) ; P<0.05]$, whereas the response in aorta from young rats treated with $\mathrm{ABH}$ was not significantly different from YC rats $(n=7, P>0.05)$ (Fig. $7 A)$.

The response to the endothelial-independent vasodilator SNP shows significantly different vasodilator response at SNP
$10 \mathrm{nmol} / \mathrm{l}$ in young rats (YC, YABH) compared with that shown in old rats $(\mathrm{OC}, \mathrm{OABH})(P<0.05, n=7)$ (Fig. $7 B)$. However, $\mathrm{E}_{\max }$ was essentially unchanged in all four groups (OC, OABH, YC, and YABH). These results suggest that endothelial-dependent change appears to be a major contributor to the aging-related vascular changes.

Chronic arginase inhibition restores arterial compliance. Because arterial compliance is a marker of vascular health and it can be modulated acutely and chronically by NO, we investigated the effect of chronic arginase inhibition on vascular stiffness. Overall, OC had a significantly lower arterial compliance (higher PWV) than control young rats [pretreatment, OC vs. YC: $6.4 \pm 0.2 \mathrm{~m} / \mathrm{s}(n=7)$ vs. $4.2 \pm 0.2 \mathrm{~m} / \mathrm{s}(n=7)$; $P<0.001$ ] (Fig. 8). After 25 days of treatment with the 

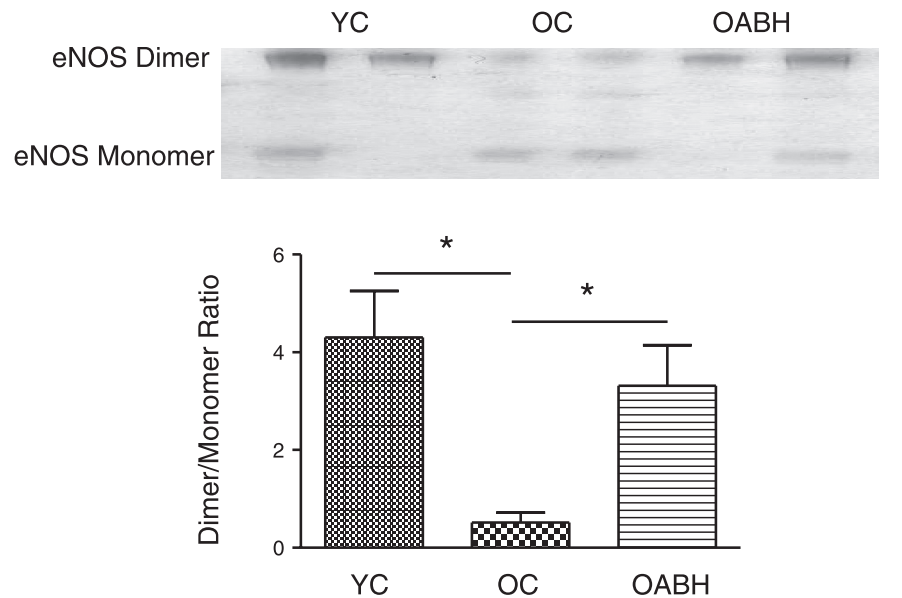

Fig. 6. Native $4^{\circ} \mathrm{C}$ polyacrylamide gel electrophoresis and Western blot for eNOS to determine eNOS dimerization in $\mathrm{YC}, \mathrm{OC}$, and $\mathrm{OABH}$ rats. In $\mathrm{OC}$ rats, dimer bands of eNOS were significantly decreased compared with young rats (YC vs. $\mathrm{OC}: 4.3 \pm 1.0$ vs. $0.5 \pm 0.2 ; n=5, * P<0.05$ ). Arginase inhibition with $\mathrm{ABH}$ prevented the decrease in eNOS dimer bands in old rats (OC vs. OABH: $0.5 \pm 0.2$ vs. $3.3 \pm 1.0 ; n=5$ or $6, * P<0.05$ ).

arginase inhibitor, PWVs were significantly reduced in old rats compared with that shown for pretreatment values $[\mathrm{OABH}$, pre- vs. posttreatment: $6.6 \pm 0.2 \mathrm{~m} / \mathrm{s}(n=7)$ vs. $4.8 \pm 0.1 \mathrm{~m} / \mathrm{s}$ $(n=7) ; P<0.05]$ and compared with OC [posttreatment, OC vs. $\mathrm{OABH}: 6.5 \pm 0.2 \mathrm{~m} / \mathrm{s}(n=7)$ vs. $4.8 \pm 0.1 \mathrm{~m} / \mathrm{s}(n=7)$; $P<0.001]$. In fact, ABH treatment significantly reduced vascular stiffness in old rats toward that of young rats [posttreatment, OABH vs. YC: $4.8 \pm 0.1 \mathrm{~m} / \mathrm{s}(n=7)$ vs. $4.9 \pm 0.1$ $\mathrm{m} / \mathrm{s}(n=7) ; P>0.05]$.

\section{DISCUSSION}

The primary findings of this study are that iNOS induction and arginase activation contribute to eNOS uncoupling in the aged rat aortic endothelium. This arginase-induced eNOS uncoupling leads to increased ROS production, which promotes endothelial dysfunction and arterial stiffening. We have demonstrated that in vivo chronic arginase inhibition restores eNOS coupling and improves endothelial function and arterial compliance in aging vasculature.

Aging itself significantly increases cardiovascular morbidity without other risk factors. Recent studies have demonstrated that aging promotes a proinflammatory microenvironment by producing a wide range of cytokines $(17,52)$. This results in the expression of iNOS, as observed in this aging rat model, and is consistent with other studies $(14,18)$. Interestingly, this induction of iNOS is confined predominantly, but not exclusively to the endothelium (45). We previously confirmed that enhanced endothelial iNOS mediates nitrosylation and activation of Arg1 in aorta of aging rats (45). A recent study (29) found that iNOS specifically binds to and $S$-nitrosylates cyclooxygenase 2 , enhancing cyclooxygenase 2 catalytic activity. Another recent study demonstrated that iNOS derived NO $S$-nitrosylates and activates cytosolic phospholipase $\mathrm{A}_{2}$ in human cells (56). These studies provide evidence for the link between nitrosylation and enzyme activation in specific "inflammatory" microenvironments. In an analogous manner, endothelial iNOS mediates SNO and activation of Arg1 in aorta of aging rats. Indeed, we have demonstrated that iNOS coim- munoprecipitates with Arg1 in both lipopolysaccharide/ $\gamma$-IFNstimulated macrophage and endothelial cell lines. Moreover the domains mediating this protein-protein interaction have been elucidated (unpublished data).

Vascular ROS production is enhanced in aged blood vessels $(2,12,52,53)$. There are four primary enzyme systems that contribute to increased production of ROS in various pathophysiological states: xanthine oxidase, NADH/NADPH oxidase, eNOS, and the mitochondrial electron transport chain (13). Although eNOS normally produces the vasoprotectant molecule, $\mathrm{NO}$, in the absence of either L-arginine or $\mathrm{BH} 4$, eNOS can produce $\mathrm{O}_{2}^{-}$. This phenomenon has been referred to as NOS uncoupling $(30,49)$. There is a growing body of evidence that eNOS uncoupling in aging plays a crucial role in the phenomenon of increased ROS production. This can be normalized by eNOS inhibition or removal of the endothelium (28). In support of our hypothesis, OC carotid arteries exhib-

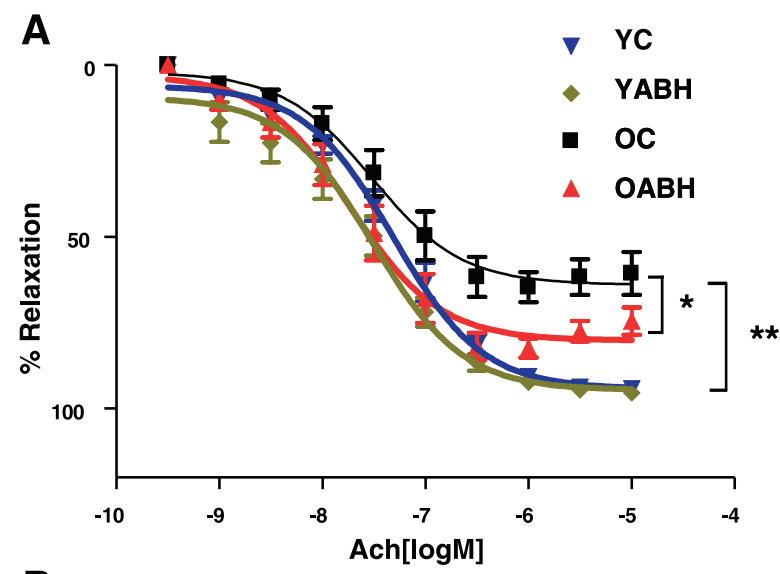

B

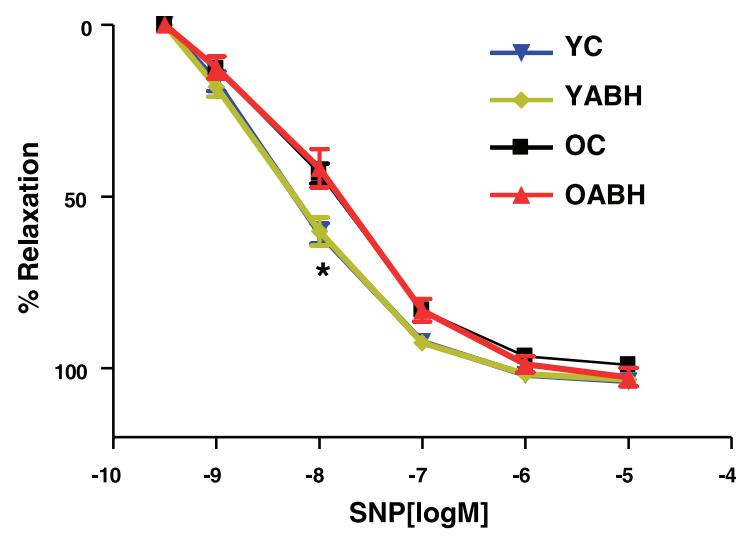

Fig. 7. Arginase inhibition improves endothelial function in old rats. Vasodilator dose responses to the endothelial-dependent vasodilator $\mathrm{ACh}(1 \mathrm{nmol} / \mathrm{l}$ to $10 \mu \mathrm{mol} / \mathrm{l})$ and endothelial-independent vasodilator sodium nitroprusside (SNP; $1 \mathrm{mmol} / \mathrm{l}$ to $10 \mu \mathrm{mol} / \mathrm{l}$ ) in phenylephrine (PE; $1 \mu \mathrm{mol} / \mathrm{l}$ )-preconstricted thoracic aortic rings from $\mathrm{YABH}$ and $\mathrm{OABH}$ rats are shown. $A$ : maximal response $\left(\mathrm{E}_{\max }\right)$ to $\mathrm{ACh}$ was significantly attenuated in $\mathrm{OC}$ rats [OC vs. YC: $64.0 \pm 2.6 \%(n=7)$ vs. $94.3 \pm 1.8 \%(n=7) ; * * P<0.01]$. Response to ACh in OABH was significantly greater than that shown in OC rats [OABH vs. OC: $80.3 \pm 2.4 \%(n=7)$ vs. $64.0 \pm 2.6 \%(n=7) ; P<0.05]$, whereas the response in aorta from YABH was not significantly different from YC rats $\left(n=7,{ }^{*} P>\right.$ $0.05)$. $B$ : in contrast, the response to the endothelial-independent vasodilator SNP approached $100 \%$ and shows essentially unchanged $\mathrm{E}_{\max }$ in all 4 groups $(\mathrm{OC}, \mathrm{OABH}, \mathrm{YC}$, and $\mathrm{YABH})$. However, a small but significant difference in vasodilator response is observed at $10 \mathrm{nmol} / \mathrm{l} \mathrm{SNP}$ in young rats (YC, YABH) compared with that shown in old rats $(\mathrm{OC}, \mathrm{OABH})(P<0.05, n=7)$. 


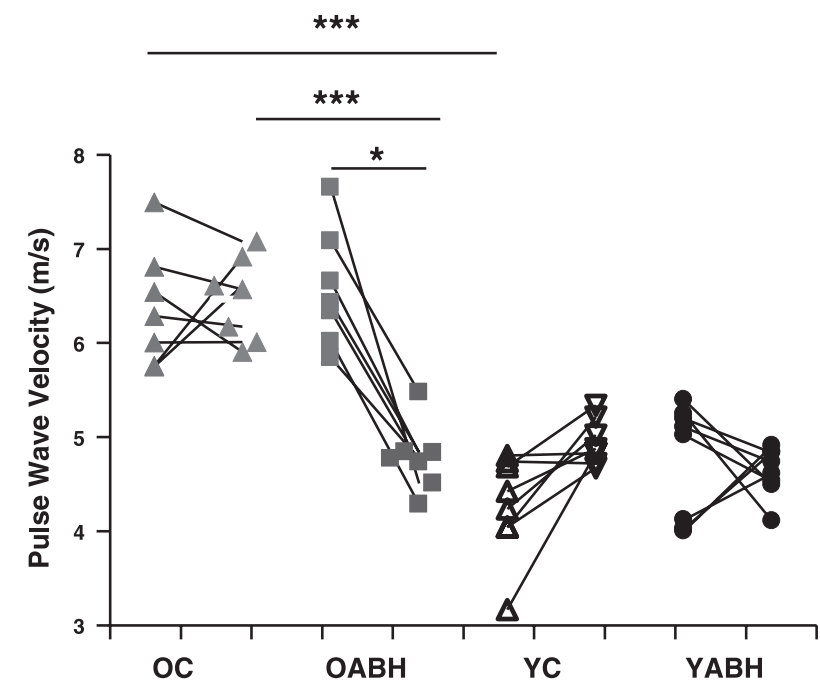

Fig. 8. Pulse wave velocities (PWVs) of individual rats before and after treatment with the arginase inhibitor $\mathrm{ABH}$ for 25 days. Results for both young and old rats are illustrated. The baseline PWV was significantly increased in old rats compared with that shown in young rats [pretreatment, OC vs. YC: $6.4 \pm 0.2 \mathrm{~m} / \mathrm{s}(n=7)$ vs. $4.2 \pm 0.2 \mathrm{~m} / \mathrm{s}(n=7) ; * * * P<0.001]$. After a 25 -day treatment with the arginase inhibitor, PWVs were significantly reduced in old rats compared with pretreatment values $[\mathrm{OABH}$, pre- vs. posttreatment: $6.6 \pm$ $0.2 \mathrm{~m} / \mathrm{s}(n=7)$ vs. $4.8 \pm 0.1 \mathrm{~m} / \mathrm{s}(n=7) ; * P<0.05]$ and compared with OC [posttreatment, OC vs. OABH: $6.5 \pm 0.2 \mathrm{~m} / \mathrm{s}(n=7)$ vs. $4.8 \pm 0.1 \mathrm{~m} / \mathrm{s}(n=$ $7) ; * * * P<0.001]$. In fact, $\mathrm{ABH}$ treatment significantly reduced vascular stiffness in old rats toward that of young rats [OABH vs. YC: $4.8 \pm 0.1 \mathrm{~m} / \mathrm{s}$ $(n=7)$ vs. $4.9 \pm 0.1 \mathrm{~m} / \mathrm{s}(n=7) ; P>0.05]$. Placebo in $\mathrm{YC}$ and $\mathrm{OC}$ had no effect.

ited a significant decrease in $\mathrm{NO}$ production and higher $\mathrm{O}_{2}^{-}$ production than shown in $\mathrm{YC}$ rats. Acute inhibition of eNOS with L-NAME led to a significant reduction of ROS production in OC. The ratio of eNOS dimer to monomer in OC was significantly decreased compared with that shown in YC. This suggests that eNOS uncoupling is the source of the endothelial ROS in the aging blood vessels. Together, these data suggest that eNOS uncoupling is an important contributor to an agerelated endothelial dysfunction.

There are a number of potential reasons why eNOS might be uncoupled and thus lead to increased ROS production in aging (49). Oxidative stress may lead to excessive oxidation and depletion of $\mathrm{BH} 4$, which contribute to eNOS uncoupling (36). This is supported by the work of Delp et al. (20) in aging rat skeletal muscle arteriole. On the other hand, the oxidation of BH4 does not appear to be an important mechanism underlying vasomotor dysfunction in aged mouse arteries (9). Levels of BH4 and its oxidation products were not different between young and aged mouse tissues. The discrepancy in these studies might be related to the vessel type (conduit vs. small resistant) or might be a function of species differences. Thus, further studies are needed to determine the relative contribution of BH4 cofactor depletion in age-dependent eNOS uncoupling.

Limited L-arginine availability also promotes uncoupling of eNOS (10). Arginase upregulation can decrease L-arginine concentrations and has been shown to contribute to the pathophysiology of disease processes, such as aging $(6,7,42,55)$, hypertension $(26,59)$, atherosclerosis $(40,41,58)$, the erectile dysfunction of diabetes (8), asthma $(34,60)$, and diabetesinduced coronary vascular dysfunction (39).
Interestingly, eNOS abundance (14) is not significantly increased in this study, and this is consistent with other studies $(16,46,47)$. Loss of eNOS activity may be an important contributor to aging-related endothelial dysfunction despite little change in eNOS protein content between studies. Furthermore, the abundance of Arg1 is also not significantly increased in this study. Although in the Wistar aging model we had demonstrated a small but significant increase in Arg1 expression (55), this appears not to be the case in the Fischer 344 model. There is however a clear increase in the abundance of iNOS in the old rats compared with that shown in young. We have previously demonstrated an increase in iNOS-dependent SNO-Arg1 in aging rat aorta, which leads to an increase in the enzymatic activity (45). Considering our current and previous findings in aging rats, it follows that iNOS is responsible for Arg1 nitrosylation and thus activation in the aged vasculature. Thus our data suggest that an increase in arginase activity contributes to eNOS uncoupling, leading to reduced NO and augmented ROS production.

It is interesting to consider why $\mathrm{NO}$ as measured by DAF fluorescence is decreased in the vasculature of aging rats despite an increase in the expression of iNOS. We suspect that this observation is indeed due to uncoupled NOS in which iNOS-dependent $\mathrm{NO}$ might react very rapidly with $\mathrm{O}_{2}^{-}$to form $\mathrm{ONOO}^{-}(18,53)$. It is also possible that, in the presence of activated arginase, iNOS is itself uncoupled, leading to enhanced $\mathrm{O}_{2}^{-}$and reduced $\mathrm{NO}$ production.

The results in Fig. $2 A$ demonstrate that chronic arginase inhibition with $\mathrm{ABH}$ can restore $\mathrm{NO}$ production in old vessels to $\sim 90 \%$ of young rats. In regard to the effects of chronic $\mathrm{ABH}$ treatment on ROS (Fig. 4A), results demonstrate that $\mathrm{ABH}$ reduces ROS levels even further. Specifically, the increased NO would be expected to result in some degree of superoxide scavenging, which is manifested as ROS levels below baseline. A consequence of the enhanced $\mathrm{NO}$ is a more robust impairment of detectable ROS compared with the NO effects.

Chronic arginase inhibition significantly improved but did not completely restore the maximal vasorelaxant response in aged aortic rings (80.3\% OABH vs. $94.3 \%$ YC). Impaired NO signaling as a result of arginase upregulation may be just one of a number of mechanisms that are dysregulated in the aging vasculature (54). Aging induces a progressive reduction in the participation of NO, endothelium-derived hyperpolarizing factor, and prostacyclin (37). This may explain the partial restoration of vasorelaxation to $\mathrm{ACh}$ in aging aorta by chronic inhibition of arginase.

The response to the endothelial-independent vasodilator SNP shows small attenuation in response at $10 \mathrm{nmol} / \mathrm{l}$ in old rats $(\mathrm{OC}, \mathrm{OABH})$ compared with young rats $(\mathrm{YC}, \mathrm{YABH})$ $(P<0.05, n=7)$. This result was similar to that seen in a previous study (48). This suggests that not only endothelialdependent but also endothelial-independent factors contribute to the aged phenotype. A potential explanation could be ageand arginase-induced vascular remodeling. Arginase activation contributes to increased production of proline and polyamine, which are associated with collagen and smooth muscle proliferation, respectively (22). Therefore, arginase activation contributes to age-dependent vascular stiffening through this mechanism (43). Conduit arteries (aorta, carotid, iliac, femoral, and brachial) become stiffer with age because elastin becomes fragmented, degraded, and replaced by much stiffer collagen. 
Furthermore, both proteins become stiffer as a result of crosslinking and calcification (25). The inhibition of NOS with L-NAME in an animal model is associated with tissue transglutaminase (tTG) activation (our unpublished data), which gives rise to small artery remodeling (38). By this mechanism, tTG activation contributes to age-related arterial stiffness. Although chronic arginase inhibition improves endothelialdependent function, it does not reverse tTG-induced crosslinking changes in protein. Other studies are not consistent with our finding in that the endothelial-independent vasodilatory response to SNP did not show any difference of $\mathrm{EC}_{50}$ between young and old rats $(46,47)$. Although the endothelialindependent vasodilatory response showed a small difference of $\mathrm{EC}_{50}$ in this study, endothelial-dependent change appears to be the major contributor to the aging-related vascular alterations.

Measures of central vascular stiffness are emerging as critical indexes of "vascular health." Moreover, these indexes appear to be the most sensitive predictors of cardiovascular events, e.g., myocardial infarction $(11,31,32)$, stroke (32), and efficacy of anti-hypertensive therapy in decreasing cardiovascular events (51). Very few therapies specifically targeting central vascular stiffness have been tested (27). Our data demonstrating that $\mathrm{ABH}$ decreases aortic PWV, a measure of vascular stiffness, to that of the healthy young rats, is therefore intriguing. This suggests that arginase may well be a critical therapeutic target with regard to aging and vascular stiffness, with our measurements yielding clinically promising results. In this series of experiments, we confirmed our previous finding that NO signaling is impaired in old rats and that this can be restored through arginase inhibition $(6,45,55)$.

In summary, the present findings demonstrate that arginase upregulation by iNOS-dependent nitrosylation leads to eNOS uncoupling and that in vivo chronic inhibition of arginase restores nitroso-redox balance, endothelial function, and vascular compliance in aging. Thus arginase may be a valuable therapeutic target in age-dependent vascular stiffness.

\section{ACKNOWLEDGMENTS}

We thank Dr. Lacy A. Holowatz of Pennsylvania State University for the helpful comments and review.

\section{GRANTS}

This work was supported by National Institutes of Health Grants R01 AG-021523 (D. E. Berkowitz) and GM-49758 (D. W. Christianson), National Space Biomedical Research Institute Grant CA00405 through NASA (A. Shoukas), and Grant NNH04ZUU005N from NASA.

\section{DISCLOSURES}

D. E. Berkowitz and D. W. Christianson are scientific founders of and consultants for Arginetix, a biotechnology company whose goal is the development of arginase inhibitors for use in vascular disease.

\section{REFERENCES}

1. Abbate A, Santini D, Biondi-Zoccai GG, Scarpa S, Vasaturo F, Liuzzo G, Bussani R, Silvestri F, Baldi F, Crea F, Biasucci LM, Baldi A. Cyclo-oxygenase-2 (COX-2) expression at the site of recent myocardial infarction: friend or foe? Heart 90: 440-443, 2004.

2. Abe J.-I., Berk BC. Reactive oxygen species as mediators of signal transduction in cardiovascular disease. Trends Cardiovasc Med 8: 59-64, 1998.

3. Adler A, Messina E, Sherman B, Wang Z, Huang H, Linke A, Hintze TH. NAD(P)H oxidase-generated superoxide anion accounts for reduced control of myocardial $\mathrm{O}_{2}$ consumption by $\mathrm{NO}$ in old Fischer 344 rats. Am J Physiol Heart Circ Physiol 285: H1015-H1022, 2003.

4. Ash DE. Structure and function of arginases. J Nutr 134: 2760S-2764, 2004.

5. Baggio R, Elbaum D, Kanyo ZF, Carroll PJ, Cavalli RC, Ash DE, Christianson DW. Inhibition of $\mathrm{Mn}^{2+}{ }_{2}$-arginase by borate leads to the design of a transition state analogue inhibitor, 2(S)-amino-6-boronohexanoic acid. J Am Chem Soc 119: 8107-8108, 1997.

6. Berkowitz DE, White R, Li D, Minhas KM, Cernetich A, Kim S, Burke S, Shoukas AA, Nyhan D, Champion HC, Hare JM. Arginase reciprocally regulates nitric oxide synthase activity and contributes to endothelial dysfunction in aging blood vessels. Circulation 108: 20002006, 2003.

7. Bivalacqua TJ, Burnett AL, Hellstrom WJ, Champion HC. Overexpression of arginase in the aged mouse penis impairs erectile function and decreases eNOS activity: influence of in vivo gene therapy of antiarginase. Am J Physiol Heart Circ Physiol 292: H1340-H1351, 2007.

8. Bivalacqua TJ, Hellstrom WJG, Kadowitz PJ, Champion HC. Increased expression of arginase II in human diabetic corpus cavernosum: in diabetic-associated erectile dysfunction. Biochem Biophys Res Commun 283: 923-927, 2001.

9. Blackwell KA, Sorenson JP, Richardson DM, Smith LA, Suda O, Nath K, Katusic ZS. Mechanisms of aging-induced impairment of endothelium-dependent relaxation: role of tetrahydrobiopterin. Am J Physiol Heart Circ Physiol 287: H2448-H2453, 2004.

10. Boeger RH, Bode-Boeger SM. Asymmetric dimethylarginine, derangements of the endothelial nitric oxide synthase pathway, and cardiovascular diseases. Semin Thromb Hemost 26: 539-546, 2000.

11. Boutouyrie P, Tropeano AI, Asmar R, Gautier I, Benetos A, Lacolley $\mathbf{P}$, Laurent $\mathbf{S}$. Aortic stiffness is an independent predictor of primary coronary events in hypertensive patients: a longitudinal study. Hypertension 39: 10-15, 2002.

12. Brandes RP, Fleming I, Busse R. Endothelial aging. Cardiovasc Res 66: 286-294, 2005.

13. Cai H, Harrison DG. Endothelial dysfunction in cardiovascular diseases: The role of oxidant stress. Circ Res 87: 840-844, 2000.

14. Cernadas MR, de Miguel LS, Garcia-Duran M, Gonzalez-Fernandez F, Millas I, Monton M, Rodrigo J, Rico L, Fernandez P, de Frutos T, Rodriguez-Feo JA, Guerra J, Caramelo C, Casado S, Lopez-Farre A. Expression of constitutive and inducible nitric oxide synthases in the vascular wall of young and aging rats. Circ Res 83: 279-286, 1998.

15. Chicoine LG, Paffett ML, Young TL, Nelin LD. Arginase inhibition increases nitric oxide production in bovine pulmonary arterial endothelial cells. Am J Physiol Lung Cell Mol Physiol 287: L60-L68, 2004.

16. Chou TC, Yen MH, Li CY, Ding YA. Alterations of nitric oxide synthase expression with aging and hypertension in rats. Hypertension 31: 643648, 1998.

17. Csiszar A, Pacher P, Kaley G, Ungvari Z. Role of oxidative and nitrosative stress, longevity genes and poly (ADP-ribose) polymerase in cardiovascular dysfunction associated with aging. Curr Vasc Pharmacol 3: 285-291, 2005.

18. Csiszar A, Ungvari Z, Edwards JG, Kaminski P, Wolin MS, Koller A, Kaley G. Aging-induced phenotypic changes and oxidative stress impair coronary arteriolar function. Circ Res 90: 1159-1166, 2002.

19. Csiszar A, Wang M, Lakatta EG, Ungvari Z. Inflammation and endothelial dysfunction during aging: role of NF-кB. J Appl Physiol 105: 1333-1341, 2008.

20. Delp MD, Behnke BJ, Spier SA, Wu G, Muller-Delp JM. Ageing diminishes endothelium-dependent vasodilatation and tetrahydrobiopterin content in rat skeletal muscle arterioles. J Physiol 586: 1161-1168, 2008.

21. Di Costanzo L, Sabio G, Mora A, Rodriguez PC, Ochoa AC, Centeno F, Christianson DW. Crystal structure of human arginase I at $1.29-\AA$ resolution and exploration of inhibition in the immune response. Proc Natl Acad Sci USA 102: 13058-13063, 2005.

22. Durante W, Johnson FK, Johnson RA. Arginase: a critical regulator of nitric oxide synthesis and vascular function. Clin Exp Pharmacol Physiol 34: 906-911, 2007.

23. Finkel T, Holbrook NJ. Oxidants, oxidative stress and the biology of ageing. Nature 408: 239-247, 2000.

24. Forstermann U, Munzel T. Endothelial nitric oxide synthase in vascular disease: from marvel to menace. Circulation 113: 1708-1714, 2006.

25. Greenwald SE. Ageing of the conduit arteries. J Pathol 211: 157-172, 2007. 
26. Johnson FK, Johnson RA, Peyton KJ, Durante W. Arginase inhibition restores arteriolar endothelial function in Dahl rats with salt-induced hypertension. Am J Physiol Regul Integr Comp Physiol 288: R1057R1062, 2005.

27. Kass DA, Shapiro EP, Kawaguchi M, Capriotti AR, Scuteri A, deGroof RC, Lakatta EG. Improved arterial compliance by a novel advanced glycation end-product crosslink breaker. Circulation 104: 14641470, 2001.

28. Kerr S, Brosnan MJ, McIntyre M, Reid JL, Dominiczak AF, Hamilton CA. Superoxide anion production is increased in a model of genetic hypertension : role of the endothelium. Hypertension 33: 1353-1358, 1999.

29. Kim SF, Huri DA, Snyder SH. Inducible nitric oxide synthase binds, S-nitrosylates, and activates cyclooxygenase-2. Science 310: 1966-1970, 2005.

30. Landmesser U, Dikalov S, Price SR, McCann L, Fukai T, Holland SM, Mitch WE, Harrison DG. Oxidation of tetrahydrobiopterin leads to uncoupling of endothelial cell nitric oxide synthase in hypertension. J Clin Invest 111: 1201-1209, 2003

31. Madhavan S, Ooi WL, Cohen H, Alderman MH. Relation of pulse pressure and blood pressure reduction to the incidence of myocardial infarction. Hypertension 23: 395-401, 1994.

32. Mattace-Raso FU, van der Cammen TJ, Hofman A, van Popele NM, Bos ML, Schalekamp MA, Asmar R, Reneman RS, Hoeks AP, Breteler MM, Witteman JC. Arterial stiffness and risk of coronary heart disease and stroke: the Rotterdam study. Circulation 113: 657-663, 2006

33. Meaume S, Benetos A, Henry OF, Rudnichi A, Safar ME. Aortic pulse wave velocity predicts cardiovascular mortality in subjects $>70$ years of age. Arterioscler Thromb Vasc Biol 21: 2046-2050, 2001.

34. Meurs H, Maarsingh H, Zaagsma J. Arginase and asthma: novel insights into nitric oxide homeostasis and airway hyperresponsiveness. Trends Pharmacol Sci 24: 450-455, 2003.

35. Miller SJ, Watson WC, Kerr KA, Labarrere CA, Chen NX, Deeg MA, Unthank JL. Development of progressive aortic vasculopathy in a rat model of aging. Am J Physiol Heart Circ Physiol 293: H2634-H2643, 2007.

36. Milstien S, Katusic Z $\mathbf{Z}$. Oxidation of tetrahydrobiopterin by peroxynitrite: implications for vascular endothelial function. Biochem Biophys Res Commun 263: 681-684, 1999.

37. Oguzhan Y. Vascular smooth muscle and endothelial functions in aging. Ann NY Acad Sci 1100: 353-360, 2007.

38. Pistea A, Bakker EN, Spaan JAE, Hardeman MR, van Rooijen N, VanBavel E. Small artery remodeling and erythrocyte deformability in L-NAME-induced hypertension: role of transglutaminases. J Vasc Res 45: 10-18, 2008.

39. Romero MJ, Platt DH, Tawfik HE, Labazi M, El-Remessy AB, Bartoli M, Caldwell RB, Caldwell RW. Diabetes-induced coronary vascular dysfunction involves increased arginase activity. Circ Res 102: 95-102, 2008.

40. Ryoo S, Gupta G, Benjo A, Lim HK, Camara A, Sikka G, Lim HK, Sohi J, Santhanam L, Soucy K, Tuday E, Baraban E, Ilies M, Gerstenblith G, Nyhan D, Shoukas A, Christianson DW, Alp NJ, Champion HC, Huso D, Berkowitz DE. Endothelial arginase II: a novel target for the treatment of atherosclerosis. Circ Res 102: 923-932, 2008.

41. Ryoo S, Lemmon CA, Soucy KG, Gupta G, White AR, Nyhan D, Shoukas A, Romer LH, Berkowitz DE. Oxidized low-density lipoprotein-dependent endothelial arginase II activation contributes to impaired nitric oxide signaling. Circ Res 99: 951-960, 2006.

42. Sakai Y, Masuda H, Kihara K, Kurosaki EMI, Yamauchi Y, Azuma H. Involvement of increased arginase activity in impaired cavernous relaxation with aging in the rabbit. J Urol 172: 369-373, 2004.

43. Santhanam L, Christianson DW, Nyhan D, Berkowitz DE. Arginase and vascular aging. J Appl Physiol 105: 1632-1642, 2008.

44. Santhanam L, Gucek M, Brown TR, Mansharamani M, Ryoo S, Lemmon CA, Romer L, Shoukas AA, Berkowitz DE, Cole RN. Selec- tive fluorescent labeling of $S$-nitrosothiols ( $S$-FLOS): a novel method for studying S-nitrosation. Nitric Oxide 19: 295-302, 2008.

45. Santhanam L, Lim HK, Lim HK, Miriel V, Brown T, Patel M, Balanson S, Ryoo S, Anderson M, Irani K, Khanday F, Di Costanzo L, Nyhan D, Hare JM, Christianson DW, Rivers R, Shoukas A, Berkowitz DE. Inducible NO synthase dependent $S$-nitrosylation and activation of arginase 1 contribute to age-related endothelial dysfunction. Circ Res 101: 692-702, 2007.

46. Smith AR, Francesco V, Balz F, Hagen TM. Age-related changes in endothelial nitric oxide synthase phosphorylation and nitric oxide dependent vasodilation: evidence for a novel mechanism involving sphingomyelinase and ceramide-activated phosphatase 2A. Aging Cell 5: 391-400, 2006

47. Smith AR, Visioli F, Hagen TM. Plasma membrane-associated endothelial nitric oxide synthase and activity in aging rat aortic vascular endothelia markedly decline with age. Arch Biochem Biophys 454: 100-105, 2006.

48. Soucy KG, Ryoo S, Benjo A, Lim HK, Gupta G, Sohi JS, Elser J, Aon MA, Nyhan D, Shoukas AA, Berkowitz DE. Impaired shear stressinduced nitric oxide production through decreased NOS phosphorylation contributes to age-related vascular stiffness. J Appl Physiol 101: 17511759, 2006.

49. Stuehr D, Pou S, Rosen GM. Oxygen reduction by nitric-oxide synthases. J Biol Chem 276: 14533-14536, 2001.

50. Takimoto E, Champion HC, Li M, Ren S, Rodriguez ER, Tavazzi B, Lazzarino G, Paolocci N, Gabrielson KL, Wang Y. Oxidant stress from nitric oxide synthase-3 uncoupling stimulates cardiac pathologic remodeling from chronic pressure load. J Clin Invest 115: 1221-1231, 2005.

51. The CI, for the Anglo-Scandinavian Cardiac Outcomes Trial I, Committee CS, Writing C, Williams B, Lacy PS, Thom SM, Cruickshank K, Stanton A, Collier D, Hughes AD, Thurston H, O'Rourke M. Differential impact of blood pressure-lowering drugs on central aortic pressure and clinical outcomes: principal results of the conduit artery function evaluation (CAFE) study. Circulation 113: 1213-1225, 2006.

52. Ungvari Z, Csiszar A, Kaley G. Vascular inflammation in aging. Herz 29: 733-740, 2004.

53. van der Loo B, Labugger R, Skepper JN, Bachschmid M, Kilo J, Powell JM, Palacios-Callender M, Erusalimsky JD, Quaschning T, Malinski T, Gygi D, Ullrich V, Luscher TF. Enhanced peroxynitrite formation is associated with vascular aging. J Exp Med 192: 1731-1744, 2000 .

54. Vanhoutte PM. Ageing and endothelial dysfunction. Eur Heart J (Suppl A) 4: A8-A17, 2002.

55. White AR, Ryoo S, Li D, Champion HC, Steppan J, Wang D, Nyhan D, Shoukas AA, Hare JM, Berkowitz DE. Knockdown of arginase I restores NO signaling in the vasculature of old rats. Hypertension 47: 245-251, 2006.

56. Xu L, Han C, $\operatorname{Lim} \mathbf{K}$, Wu T. Activation of cytosolic phospholipase $A_{2} \alpha$ through nitric oxide-induced S-nitrosylation: involvement of inducible nitric-oxide synthase and cyclooxygenase-2. J Biol Chem 283: 3077-3087, 2008.

57. Xu L, Hilliard B, Carmody RJ, Tsabary G, Shin H, Christianson DW, Chen YH. Arginase and autoimmune inflammation in the central nervous system. Immunology 110: 141-148, 2003.

58. Yang Z, Ming XF. Endothelial arginase: a new target in atherosclerosis. Curr Hypertens Rep 8: 54-59, 2006.

59. Zhang C, Hein TW, Wang W, Miller MW, Fossum TW, McDonald MM, Humphrey JD, Kuo L. Upregulation of vascular arginase in hypertension decreases nitric oxide-mediated dilation of coronary arterioles. Hypertension 44: 935-943, 2004.

60. Zimmermann N, King NE, Laporte J, Yang M, Mishra A, Pope SM, Muntel EE, Witte DP, Pegg AA, Foster PS. Dissection of experimental asthma with DNA microarray analysis identifies arginase in asthma pathogenesis. J Clin Invest 111: 1863-1874, 2003. 